\title{
Postural analysis and psychosocial measurements of federal civil servants of an institution of higher education
}

\author{
Rodrigo Carregaro ${ }^{\text {a, }}$, Juliano Falcão ${ }^{a}$, Karlla Massuda ${ }^{a}$, Daniely Masunaga ${ }^{a}$, Camila Sinzato ${ }^{a}$, Ana \\ Beatriz de Oliveira ${ }^{b}$, Rosimeire S Padula ${ }^{\mathrm{c}}$ \\ ${ }^{a}$ School of Physical Therapy, Universidade Federal de Mato Grosso do Sul (UFMS), Campo Grande, MS, Brazil. \\ ${ }^{b}$ Graduate Program in Physical Therapy, Universidade Federal de São Carlos (UFSCar), São Paulo,Brazil \\ ${ }^{c}$ Masters in Physical Therapy Program, Universidade Cidade de São Paulo, R. Cesário Galeno, 448, São Paulo, \\ Brazil
}

\begin{abstract}
The aim was to evaluate work engagement (WE), ratings of perceived exertion (RPE), postural deviations and to characterize musculoskeletal symptoms of federal civil servants of an institution of higher education. Methods. Twenty four women (age $40.0 \pm 11.2$ years, $1.6 \pm 0.1 \mathrm{~m}, 66.6 \mathrm{~kg} \pm 10.0 \mathrm{~kg}$ ) and 13 men (age $38.3 \pm 10.3$ years, $1.7 \pm 0.1 \mathrm{~m}, 84.3 \mathrm{~kg} \pm 19.1 \mathrm{~kg}$ ) were recruited. The Nordic Questionnaire was used to evaluate musculoskeletal symptoms and the Borg Scale for the RPE. WE was quantified by the Utrecht Work Engagement Scale (vigor, dedication and absorption domains). Posture was assessed by photogrammetry and analyzed with the Postural Assessment Software (PAS/SAPO). The independent student t test was used to verify WE and postural differences and the chi-square test to verify RPE and symptoms' differences between genders. Results. All subjects reported musculoskeletal complaints, mainly in the low back (28.4\%). Women presented more musculoskeletal complaints (67\%). RPE and WE did not differ between genders, however, women presented pronounced postural deviations compared to men (angle between leg and right foot dorsum, and horizontal pelvic alignment; $p<0.05$ ). Conclusion. Findings highlight the implementation of health promotion measures, such as postural reeducation and ergonomic guidelines, with specific activities according to gender.
\end{abstract}

Keywords: ergonomics, physical therapy, posture, workplace.

\section{Introduction}

Work-related musculoskeletal disorders (WRMD) are not job-specific and affect workers in a wide variety of occupations. These disorders usually take months or even years to develop and are a major cause of lost time from work, health care costs and constitute a major proportion of all registered and compensable work-related diseases in many countries resulting in pain, loss of functional capacity and work disability [1,2]. Complaints and musculoskeletal discomforts are common manifestations of individuals affected by WRMD [3]. In this sense, it is important to understand the effect of workplace and occupational activities on performance, work capacity and health. The use of instruments that provide information about functional deficits has become necessary, considering the impacts of WRMD on workers' abilities and health [4].

Physical exertion in the workplace can result in the precipitation of WRMD, and studies have shown that posture, range of motion, force and repetition are relevant determinants of physical overload [5]. When the body alignment is adequate, musculoskeletal structures are well-balanced, therefore less susceptible to injuries and deformities [6]. Thus, from a clinical perspective, body posture is an important health indicator, which can be associated with a large number of disorders, including pain syndromes or regional musculoskeletal disorders [7].

\footnotetext{
* Corresponding author. E-mail: rodrigocarregaro@yahoo.com.br. Universidade Federal de Mato Grosso do Sul, CCBS/Fisioterapia, Cidade Universitária, Av. Costa e Silva, S/N, CEP: 79070-900, Campo Grande/MS, Brazil. Tel. +55 67 3345-7837.
} 
Another influence is the individual and/or psychosocial risk factors, that also play a significant role in WRMD development [8]. Perceived exertion could be a useful index of workload and subjective experience of both time load and mental effort load [8]. The commitment or engagement to work is a psychometric variable that has been the focus of several studies because it can provide important information about human capability, especially influences on workplace performance [9].

It is noteworthy that differences in morbidity between genders shown that musculoskeletal disorders are, overall, more common in women $[10,11]$, demonstrating the importance of gender's effects on occupational health issues [12]. For example, factors such as daily computer usage, incorrect computer positioning, incorrect body posture and female gender were significantly associated with neck and low back complaints among computer office workers [13].

In this context, physical, organizational and psychosocial factors play an important role in the genesis and evolution of musculoskeletal complaints. The interaction between cognitive and physical factors must be integrated into ergonomic evaluations so that global and effective preventive actions are promoted in the occupational environment. Therefore, the aim of the present study was to evaluate the work engagement, ratings of perceived exertion (RPE) and postural deviations; and to characterize the musculoskeletal symptoms of federal civil servants of an institution of higher education. The other objectives were to compare domains of work engagement (vigor, dedication and absorption), RPE and postural asymmetries between genders.

\section{Material and Methods}

\subsection{Participants}

A convenience sample of thirty-seven subjects, 24 women (mean age $40.0 \pm 11.2$ years, $1.6 \pm 0.1 \mathrm{~m}$, $66.6 \mathrm{~kg} \pm 10.0 \mathrm{~kg}$ and body mass index of $25.8 \pm$ $3.8 \mathrm{~kg} / \mathrm{m}^{2}$ ) and 13 men (mean age $38.3 \pm 10.3$ years, $1.7 \pm 0.1 \mathrm{~m}, 84.3 \mathrm{~kg} \pm 19.1 \mathrm{~kg}$ and body mass index of $27.7 \pm 5.4 \mathrm{~kg} / \mathrm{m}^{2}$ ) were recruited to participate in the study. All workers were employed in a federal institution of higher education, performing administrative tasks at the Coordination of Human Resources.

Subjects were included if they presented 1) at least one year of occupational experience; 2) if they were official regular employees of the institution and 3) at least 18 years old. All of the studied employees had a 6 to 8 hour workday. The study protocol was approved by the institutional review board, and all subjects gave informed consent before participation.

\subsection{Musculoskeletal symptoms}

In order to record musculoskeletal symptoms related to work, a validated version of the Nordic Questionnaire was used [14, 15]. The questionnaire was adapted using structured and semi-structured questions that addressed personal data and musculoskeletal work-related symptoms from the past 12 months. A body diagram was used, and all participants were instructed to point out one or more body regions in which discomfort was present.

\subsection{Ratings of perceived exertion (RPE)}

Ratings of perceived exertion were measured with the Borg RPE Scale, based on the physical demands of their characteristic working processes. RPE scores can vary from 6 ("no exertion at all") to 20 ("maximum effort"), which represents workers' physical effort during the performance of their occupational activities. Verbal anchors were provided in order to standardize responses.

\subsection{Work engagement}

The work engagement, as adopted in the context of the present study, was determined as "a state of mind related to work, which is positive and satisfactory, marked by vigor, dedication and absorption during the performance of occupational activities". Work engagement and individual notions of commitment to work were evaluated according to the Utrecht Work Engagement Scale (UWES) [9].

The total score is computed by summing the score for each sub-category: (a) vigor, characterized by high levels of energy and persistence during work even tough difficulties are present; (b) dedication, characterized by a significant involvement with the work, i.e., pride, enthusiasm and sense of challenge from the activities; and (c) absorption, characterized by full concentration on the job. Higher scores indicate a better classification of work engagement, which can be analyzed numerically or be nominally classified as very low, low, regular, high or very high, as determined by the final score. 


\subsection{Postural analysis}

Posture was assessed by means of photogrammetry, which consisted of capturing images using a digital camera and subsequent analysis with the Postural Assessment Software (PAS/SAPO) [7, 16]. This software has been developed to assist posture assessment from digitalized pictures, which is available in the public domain. PAS/SAPO allows the measurement of distances and angles, and provides the analysis of postural deviations and the projection of the center of gravity $[7,16]$.

Anatomical points were marked using spherical markers of $15 \mathrm{~mm}$ in diameter, attached to the skin. Photographs were taken with the participants minimally dressed [16], such that it was possible to view the anatomical points, bilaterally: tragus of the ear; 7th cervical vertebra; 12th thoracic vertebra; midpoint of the acromion; anterior superior iliac spine (ASIS); posterior superior iliac spine; greater trocanter; patellar medial point; tuberosity of the tibia; lateral epicondyle of the knee; inferior angle of the scapula; medial line of the leg; Achilles tendon; lateral and medial maleolus; calcaneous prominence and the point between the head of the 2 nd and $3^{\text {rd }}$ metatarsal. Participants were instructed to adopt an orthostatic position, with their feet in parallel. The digital camera (Sony Cybershot DSC-P9, 4 megapixels) was positioned in a tripod, at a distance of 2.5 meters from the participants. A plumbline was positioned at the same plane of subjects' body, with a known measure $(50 \mathrm{~cm})$ in order to calibrate the digitalized images. Four images were captured: anterior, posterior, right and left views of the body.

For the present study, the following body alignments were calculated [7]: 1. Horizontal alignment of the head (HAH); 2. Horizontal alignment of the ASIS (HAA); 3. Frontal angle of the right and left limb (FARL and FALL); 4. Horizontal scapular asymmetry relative to the spinal process of the $3^{\text {rd }}$ thoracic vertebra - T3 (HSAT3); 5. Angle between leg and right/left foot dorsum (ALRD and ALLD); 6. Vertical alignment of the head, right and left (VAHR and VAHL); 7. Vertical alignment of the body, right and left (VABR and VABL); 8. Horizaontal pelvic alignment, right and left (HPAR and HPAL); 9. Knee angle, right and left (KAR and KAL); 10. Gravity center frontal asymmetry (GCFA) and 11. Gravity center saggital asymmetry (GCSA).

\subsection{Statistical analysis}

The Statistical Package for Social Sciences (SPSS) software version 13.0 was used for statistical analysis, with significance set at $5 \%(p<0.05)$. Data was expressed by mean and standard deviation, when normality assumptions were confirmed by the ShapiroWilk test. A student $t$ test for paired samples were applied in order to compare right and left sides of the body, for bilateral postural variables.

Subjects were divided by gender, and the student $t$ test for independent samples was applied in order to verify differences between postural and center of gravity deviations, and work engagement. Differences between genders for RPE and musculoskeletal symptoms were investigated by the chi-square test.

\section{Results}

In respect to musculoskeletal symptoms, all participants referred discomfort for at least one body region, in the past 12 months. Women presented more musculoskeletal complaints $(67 \%)$ than men did $(33 \%)$. Considering responses from all the participants, the low back presented the highest prevalence, with a frequency of $28.4 \%$ responses, followed by shoulders $(17.9 \%)$, inferior limbs $(17.9 \%)$, neck $(11.9 \%)$ and arms (10.4\%). Women's complaints demonstrated that the low back presented a frequency of $24.4 \%$, followed by inferior limbs $(20 \%)$, shoulders $(15.6 \%)$, neck (11.1\%), arms $(8.9 \%)$ and hips $(6.7 \%)$. For men, the low back also presented the highest frequency of complaints, with $36.4 \%$, followed by shoulders $(22.7 \%)$, neck $(13.6 \%)$ and arms $(13.6 \%)$.

There were no significant differences between genders for ratings of perceived exertion $(p>0.05)$. Men presented a median RPE of 11 (maximum and minimum of 17 and 6 , respectively) and women a median of 11 (maximum and minimum of 18 and 6 , respectively).

Domains of work engagement did not presented differences between genders ( $p>0.05$, Table 1$)$. However, the classification of work engagement demonstrated that for women, vigor, dedication and absorption were classified as average. On the other hand, for men, all domains were high, except for absorption that also presented an average classification.

Results from photogrammetry evaluations are presented in Table 2. Bilateral values were the same for all subjects, and results considered right side measurements. Significant differences were found be- 
tween genders for the angle between leg and right foot dorsum, and horizontal pelvic alignment $(p<0.05$, Table 2).

Table 1

Scores of work engagement (vigor, dedication and absorption domains). Values are presented as mean \pm standard deviation.

\begin{tabular}{lcccccc}
\hline & \multicolumn{7}{c}{ Work Engagement } \\
\cline { 2 - 7 } & Vigor & Class. & Dedication & Class. & Absorption & Class. \\
\hline Men & $4.80 \pm 0.67$ & High & $5.01 \pm 0.78$ & High & $4.26 \pm 1.09$ & Average \\
\hline Women & $4.68 \pm 0.67$ & Average & $4.56 \pm 0.94$ & Average & $4.10 \pm 0.82$ & Average \\
\hline Class.: nominal classification based on score. & & & \\
\hline
\end{tabular}

\section{Discussion}

The high prevalence of complaints and discomfort found in the present study, mainly associated with the low back, can be explained by tasks of the analyzed sector, in which workers perform their activities in a seated posture, with frequent keyboard use, filling out forms, organizing archives and documents, besides dealing with stressing deadlines. In this sense, complaints found in the present study may be related with important risk factors for chronic low back pain, i.e, prolonged sitting associated with asymmetrical and static postures [5, 17, 18].

Regarding RPE, the absence of gender differences demonstrated that the job functions and demands produced the same perception of physical overload. This fact should be interpreted as an important risky condition, considering that women and men have differences in their biology and physiology, employment status, job assignments, and responsibilities and activities outside work [10, 12]. Due to differences in anthropometric measurements, even the same workplace is not experienced the same way by men and women, as surface height and equipment dimensions may impose different demands on the body [12]. In fact, results from a recent study [19] revealed biomechanical differences in sitting behavior, demonstrating that males and females may be exposed to different loading patterns and may experience different injury pathways.

The present study demonstrated that gender did not impose differences on work engagement perception. This finding may be explained by the fact that work is a complex interaction of tasks, roles, responsibilities, incentives and rewards [20].

Subjects who are stimulated and pleased with their work feel capable of and excited about performing it [9]. Thus, understanding of job satisfaction and work engagement requires a more profound analysis, in terms of its constituent elements and environmental factors [20], with gender influences being one of several factors determining psychosocial responses in the workplace. Nevertheless, it is important to note that women presented lower values (representing an "average" classification for vigor, dedication and absorption). This underlies health promotion measures, such as worker participatory approaches to improve psychosocial work environment and mental health [21].

In the present study, women presented significant postural deviations compared to men, specifically, a larger angle between leg and right foot dorsum (knee valgus) and horizontal pelvic alignment (pelvic anteversion). A previous study demonstrated that work performed in the sitting position may determine structural adjustments of body tissues [22]. It is suggested that these adaptations seem to be towards shortening of the posterior muscle chain, especially bi-articular ones crossing the knee (hamstrings and gastrocnemius). This shortened position, when maintained for prolonged and frequent periods, could lead to pelvic restrictions and, consequently, to an increased pelvic anteversion [22]. However, this hypothesis cannot be fully confirmed as causal relationships are complex, and characteristics related to physical performance, flexibility and life habits should also be investigated. 
Table 2

Results from postural analysis with PAS/SAPO software. Values are presented in degrees for all variables, except for GCFA and GCSA, presented in percentage.

\begin{tabular}{|c|c|c|c|}
\hline Variable & Gender & Mean & $\begin{array}{c}\text { Std. Error } \\
\text { Mean }\end{array}$ \\
\hline \multirow{2}{*}{ НAH } & Men & 0.86 & 1.01 \\
\hline & Women & 0.87 & 0.94 \\
\hline \multirow{2}{*}{ HAA } & Men & -1.10 & 0.78 \\
\hline & Women & -0.72 & 0.56 \\
\hline \multirow{2}{*}{ FARL } & Men & -1.18 & 1.00 \\
\hline & Women & -4.47 & 0.69 \\
\hline \multirow{2}{*}{ HSAT3 } & Men & 7.38 & 3.14 \\
\hline & Women & 1.77 & 5.45 \\
\hline \multirow{2}{*}{ ALRD* } & Men & 8.94 & 1.48 \\
\hline & Women & 12.97 & 1.69 \\
\hline \multirow{2}{*}{ VAHR } & Men & 10.67 & 3.25 \\
\hline & Women & 7.10 & 2.18 \\
\hline \multirow{2}{*}{ VABR } & Men & 1.60 & 0.42 \\
\hline & Women & 0.99 & 0.24 \\
\hline \multirow{2}{*}{ HPAR* } & Men & -9.48 & 0.77 \\
\hline & Women & -14.98 & 1.28 \\
\hline \multirow{2}{*}{ KAR } & Men & -1.32 & 0.87 \\
\hline & Women & -3.18 & 1.08 \\
\hline \multirow{2}{*}{ GCFA } & Men & -1.48 & 1.67 \\
\hline & Women & -2.00 & 1.88 \\
\hline \multirow{2}{*}{ GCSA } & Men & 31.29 & 2.32 \\
\hline & Women & 28.60 & 2.69 \\
\hline
\end{tabular}

* Significant differences between genders: $p<0.05$

HAH: Horizontal alignment of the head; HAA: Horizontal alignment of the ASIS; FARL: Frontal angle of the right limb; HSAT3: Horizontal scapular asymmetry relative to the spinal process of T3; ALRD: Angle between leg and right foot dorsum; VAHR: Vertical alignment of the head, right side; VABR: Vertical alignment of the body, right; HPAR: Horizontal pelvic alignment, right; KAR: Knee angle, right; GCFA: Gravity center frontal asymmetry; GCSA: Gravity center saggital asymmetry.

Photogrammetric postural analyses are useful and reliable [7], and as adopted in the present study may represent important preventive applications. The present findings demonstrated that in the context of body posture, there is the need for gender specific actions. In this sense, postural analysis with PAS/SAPO software could be an important instrument for physiotherapists, in order to adopt specific actions such as postural reeducation therapy and physical exercise in the workplace, focusing on spe- cific gender demands and associated with a wide ergonomic intervention.

\section{Conclusion}

The present study demonstrated that perceived exertion referred during the execution of working activities from an administrative sector was not influenced by gender. Also, work engagement did not presented differences between men and women, although women presented lower values.

Those facts becomes relevant, considering that women have a greater susceptibility to risk factors related to physical overload, which underlies the implementation of health promotion measures such as postural reeducation, physical exercise and ergonomic guidelines focusing on prevention, with specific activities according to gender.

\section{References}

[1] Franco G, Fusetti L. Bernardino Ramazzini's early observations of the link between musculoskeletal disorders and ergonomic factors. Appl Ergon. 2004; 35(1):67-70.

[2] Punnett L, Wegman DH. Work-related musculoskeletal disorders: the epidemiologic evidence and the debate. J Electromyogr Kinesiol. 2004; 14(1):13-23.

[3] Augusto VG, Sampaio RF, Tirado MGA, Mancini MC, Parreira VF. Um olhar sobre as LER/DORT no contexto clínico do fisioterapeuta. Rev Bras Fisioter. 2008; 12(1):49-57.

[4] Walsh IA, Corral S, Franco RN, Canetti EE, Alem ME, Coury HJ. Work ability of subjects with chronic musculoskeletal disorders. Rev Saude Publica 2004; 38(2):149156.

[5] Vieira ER, Kumar S. Working postures: a literature review. J Occup Rehabil. 2004; 14(2):143-159.

[6] Santos MM, Silva MPC, Sanada LS, Alves CRJ. Photogrammetric postural analysis on healthy seven to ten-yearold children: interrater reliability. Rev Bras Fisioter. 2009; 13(4):350-355.

[7] Ferreira EA, Duarte M, Maldonado EP, Burke TN, Marques AP. Postural assessment software (PAS/SAPO): Validation and reliabiliy. Clinics 2010; 65(7):675-81.

[8] Hughes LE, Babski-Reeves K, Smith-Jackson T. Effects of psychosocial and individual factors on physiological risk factors for upper extremity musculoskeletal disorders while typing. Ergonomics. 2007; 50(2):261-74.

[9] Schaufeli W, Bakker A, Salanova M. The measurement of Work Engagement with a short questionnaire: A CrossNational Study. Educ Psychol Meas 2006; 66(4):701-16.

[10] Rocha LE, Debert-Ribeiro M. Work and health: a gender study on systems analysts. Rev Saúde Pública. 2001; 35(6):539-47.

[11] Bergman S. Public health perspective--how to improve the musculoskeletal health of the population. Best Pract Res Clin Rheumatol. 2007; 21(1):191-204. 
[12] Messing K, Punnett L, Bond M, Alexanderson K, Pyle J, Zahm S, et al. Be the fairest of them all: challenges and recommendations for the treatment of gender in occupational health research. Am J Ind Med. 2003; 43(6):618-29.

[13] Ranasinghe P, Perera YS, Lamabadusuriya DA, Kulatunga $\mathrm{S}$, Jayawardana N, Rajapakse S, et al. Work related complaints of neck, shoulder and arm among computer office workers: a cross-sectional evaluation of prevalence and risk factors in a developing country. Environ Health. 2011; $10: 70$.

[14] Kuorinka I, Jonsson B, Kilbom A, Vinterberg H, BieringSorensen F, Andersson G, et al. Standardised Nordic questionnaires for the analysis of musculoskeletal symptoms. Appl Ergon. 1987; 18(3):233-237.

[15] Barros EN, Alexandre NM. Cross-cultural adaptation of the Nordic musculoskeletal questionnaire. Int Nurs Rev. 2003; 50(2):101-108

[16] Burke TN, FrançaI FJR, Meneses SRF, Cardoso VI, Pereira RMR, Danilevicius CF, et al. Postural control among elderly women with and without osteoporosis: is there a difference? Sao Paulo Med J. 2010; 128(4):219-224.
[17] Lis AM, Black KM, Korn H, Nordin M. Association between sitting and occupational LBP. Eur Spine J. 2007; 16(2):283-298.

[18] Dunk NM, Callaghan JP. Lumbar spine movement patterns during prolonged sitting differentiate low back pain developers from matched asymptomatic controls. Work. 2010 35(1):3-14.

[19] Dunk NM, Callaghan JP. Gender-based differences in postural responses to seated exposures. Clin Biomech (Bristol, Avon). 2005; 20(10):1101-1110.

[20] Martinez MC, Paraguay AI, Latorre Mdo R. [Relationship between psychosocial job satisfaction and health in white collar workers]. Rev Saude Publica. 2004; 38(1):55-61.

[21] Kawakami N, Tsutsumi A. Job stress and mental health among workers in Asia and the World. J Occup Health. 2010; 52:1-3.

[22] Sacco ICN, Aliberti S, Queiroz BWC, Pripas D, Kieling I, Kimura AA, et al. The influence of occupation on overall flexibility and lower limb and lumbar range of motion. Rev Bras Cineantropom Desempenho Hum. 2009; 11(1):51-58. 